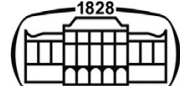

AKADÉMIAI KIADÓ

\title{
The Big Five personality traits and online gaming: A systematic review and meta-analysis
}

\section{Journal of Behavioral Addictions}

$10(2021) 3,611-625$

DOI:

$10.1556 / 2006.2021 .00050$

(c) 2021 The Author(s)

\author{
MEHDI AKBARI $^{1 *}$ (1), MOHAMMAD SEYDAVI ${ }^{1}$, \\ MARCANTONIO M. SPADA ${ }^{2}$, \\ SHAHRAM MOHAMMADKHANI ${ }^{1}$, SHIVA JAMSHIDI ${ }^{1}$, \\ ALIREZA JAMALOO $^{1}$ and FATEMEH AYATMEHR ${ }^{1}$
}

\author{
${ }^{1}$ Department of Clinical Psychology, Faculty of Psychology and Education, Kharazmi University, \\ Tehran, Iran \\ ${ }^{2}$ Division of Psychology, School of Applied Sciences, London South Bank University, London, UK \\ Received: March 21, 2021 • Revised manuscript received: June 28, 2021 • Accepted: July 7, 2021 \\ Published online: August 25, 2021
}

\begin{abstract}
Online gaming has become an essential form of entertainment with the advent of technology and a large sway of research has been undertaken to understand its various permutations. Previous reviews have identified associations between the Big Five personality traits and online gaming, but a systematic review and meta-analysis on the association between these constructs has yet to be undertaken. In the current study we aimed to fill this gap in the literature through a systematic review and meta-analysis comprising of 17 studies and 25,634 individuals $\left(\mathrm{Age}_{\text {Mean }}=26.55\right.$, males $=75 \%$ ). The findings showed that agreeableness, extraversion, openness to experience, and neuroticism were not ubiquitously associated with online gaming. The findings showed that only conscientiousness, across samples, had a protective role in online gaming. Furthermore, there were non-significant variations in the Big Five personality traits associations with online gaming when comparing gamers to the general population, younger versus older participants, casual versus 'hardcore' gamers, and high versus low traits (with the exception of neuroticism). As a result of our observations, the underlying mechanisms of individual differences in online gaming remain unclear. Limitations and future directions for research are discussed.
\end{abstract}

\section{KEYWORDS}

Big Five personality traits, meta-analysis, online gaming, systematic review.

\section{INTRODUCTION}

Online gaming has become an essential form of entertainment with the advent of technology (Wang, Ren, Long, Liu, \& Liu, 2019). People of different ages might be motivated to play games for the challenge, socialization, or relaxation (Yee, 2006). Although gaming is a pleasant activity that can have educational implications (Pontes, Stavropoulos, \& Griffiths, 2020), for a subgroup of game-players, excessive gaming results in syndromes that have been associated with addictive behaviors (Rehbein, Kliem, Baier, Mößle, \& Petry, 2015; Wang et al., 2019).

The prevalence rates of online gaming are uncertain, with studies showing wide ranges including 0.7\%-27.5\% (Mihara \& Higuchi, 2017), 0.7\%-15.6\% (Feng, Ramo, Chan, \& Bourgeois, 2017), 0.6\%-50.0\% (Paulus, Ohmann, Von Gontard, \& Popow, 2018), and 1.2\%5.9\% (Sugaya, Shirasaka, Takahashi, \& Kanda, 2019). Stevens, Dorstyn, Delfabbro, and King (2020) used meta-analytic techniques and found that the worldwide prevalence of online gaming was $3.05 \%$, but this figure was adjusted to $1.96 \%$ when their analysis was limited to studies which met more stringent sampling criteria. They referred to the study population, diagnostic criteria, and various assessment instruments as the potential causes for different prevalence rates. It has been reported that the prevalence of online gaming is higher among males than females and among younger people than older people (FAM, 2018; Jiménez- 
Murcia et al., 2014; Lemmens, Valkenburg, \& Gentile, 2015; Mentzoni et al., 2011; Paulus et al., 2018; Sugaya et al., 2019; Vollmer, Randler, Horzum, \& Ayas, 2014).

\section{Personality traits and online gaming}

Temperamental characteristics and personality traits are considered important variables that may play a role in developing and maintaining online gaming (Brand, Young, Laier, Wölfling, \& Potenza, 2016; Dieris-Hirche et al., 2020; Mihara \& Higuchi, 2017; Munno et al., 2017). Relationships between personality traits on one hand and time spent on gaming, gaming motives, and individual's preference for gaming, on the other hand, have also been observed (Chory \& Goodboy, 2011; De Hesselle, Rozgonjuk, Sindermann, Pontes, \& Montag, 2020; Dieris-Hirche et al., 2020; Montag et al., 2011; Seong, Hong, Kim, Kim, \& Han, 2019; Teng, Lo, \& Lin, 2012; Vollmer et al., 2014). Furthermore, many personality traits, such as hostility, detachment, psychoticism, self-devaluation, introversion, submissiveness, impulsivity, and interpersonal sensibility, have been reported to be highly associated with online gaming (Blinka, Škařupová, \& Mitterova, 2016; Collins, Freeman, \& Chamarro-Premuzic, 2012; Laier, Wegmann, \& Brand, 2018; Torres-Rodríguez, Griffiths, Carbonell, \& Oberst, 2018).

Investigating the relationships between the Big Five personality traits and online gaming has attracted many researchers' attention (for example, see Müller, Beutel, Egloff, \& Wölfling, 2014; De Hesselle et al., 2020; Akbari et al., 2021). The trend highlights a relevant difference in personality traits between healthy (regular) and addicted gamers, summarized as follows. Wang et al. (2015) investigated the relations between personality traits, based on the Big Five model, and gaming addiction. They found that low conscientiousness and low openness to experience were significantly associated with gaming addiction. Wittek et al. (2016) investigated a large and representative sample of Norwegian game players and found that video game addiction was positively associated with neuroticism and negatively associated with conscientiousness. Braun, Stopfer, Müller, Beutel, and Egloff (2016) used the Big Five model to compare personality traits of gaming addicts, regular gamers, and nongamers and found low neuroticism only among regular gamers. Bouna-Pyrrou et al. (2018) found a positive relationship between online gaming and neuroticism and a negative relationship between online gaming and conscientiousness. Reyes et al. (2019) studied a large sample of Filipino gamers. They found neuroticism was positively correlated with pathological gaming, while the remaining Big Five personality traits (i.e., extraversion, openness to experience, agreeableness, and conscientiousness) were negatively correlated with pathological gaming. They also found that among the Big Five personality traits, conscientiousness was the strongest predictor of pathological gaming. De Hesselle et al. (2020) studied the associations between gaming motives, time spent on gaming, and the Big Five personality traits and found positive and negative correlations among different gaming motives and various personality traits. They also found that more agreeable, extraverted, conscientious gamers tend to spend less time gaming. Dieris-Hirche et al. (2020) investigated several possible relevant psychological variables, including the Big Five personality traits among a group of 820 male and female gamers. The participants who suffered from problematic gaming behavior had significantly higher neuroticism scores and lower scores on extraversion, conscientiousness, and openness to experience. However, in terms of agreeableness, no difference was found between this group of participants and those who reported no problematic gaming behavior. Liao et al. (2020) studied a large group of Chinese adolescent game players and found a significant and positive association between online gaming and neuroticism and a meaningful and negative correlation between online gaming and conscientiousness.

\section{The aim of the current study}

Among various factors that have been identified as contributors to vulnerability to online gaming, personality traits play a critical role (Gervasi et al., 2017; Şalvarlı \& Griffiths, 2019). Within the field of personality traits, the Big Five model is the most popular typology, and a considerable number of studies have been conducted to investigate the associations between this model and online gaming (see Braun et al., 2016; Dieris-Hirche et al., 2020; Reyes et al., 2019). Gervasi et al. (2017) conducted a systematic review of literature on empirical studies published from 2007 to 2016 and found online gaming is associated to a wide range of personality disorders and traits. They emphasized the necessity of conducting further research to specify patterns of personality traits that predispose people to online gaming. A more recent review was carried out by Şalvarlı and Griffiths (2019). They analyzed published research from 2000 to 2018 and found that extraversion and openness to experience had a negative or zero association with online gaming. On the other hand, this review revealed mixed results of a positive or no association between conscientiousness, agreeableness, and neuroticism and online gaming.

Although these systematic reviews provided significant informative findings on the relationship between personality traits and online gaming, the field has expanded quickly over the last three to four years and a clearer picture of the relationship between the Big Five personality traits and online gaming may be achieved from employing a metaanalytic method. Therefore, this study aimed to fill the existing gap in the literature by conducting a comprehensive systematic review and meta-analysis on the relationship between the Big Five personality traits and online gaming.

\section{METHOD}

\section{Study selection}

The current study findings have been reported based on the Preferred Reporting Items for Systematic Reviews and MetaAnalyses (PRISMA) guidelines (Moher, Liberati, Tetzlaff, Altman, \& The PRISMAGroup, 2009). 


\section{Eligible studies for inclusion}

In order for studies to be eligible for inclusion they had to meet the following criteria: 1 ) any publication reported in English; 2) research investigating the relationship between the Big Five personality traits and online gaming; 3) research which used established measures of the Big Five personality traits; and 4) research reporting Pearson's or Spearman's $r$ correlation coefficients of the variables of interest, or any data that could be converted into a correlation coefficient, such as Cohen's d/f, T-value, or Fisher's Z. Nonetheless, we did not restrict the scope of our review by any fixed criteria to ensure that all relevant papers were considered.

\section{Search strategy}

Three independent authors systematically searched PsycINFO, PubMed, Science direct, and ProQuest without any date restriction. The following keywords "trait" OR "big five" OR "five-factor model" OR "personality trait" OR "big five personality trait" OR "five-factor personality model" OR "neo pi profiles" OR "ffm" OR "hexaco" OR "eyseneck" OR "agreeableness" OR "extraversion" OR "conscientiousness" OR "neuroticism" OR "openness" were used for the personality traits and "Internet Gaming" OR "online gaming" OR "internet game" OR "video game" OR "Computer Game" OR "Gaming Addict" OR "Gaming depend"” OR "online gaming" combined with AND Boolean operator and databases tailored search functions (e.g., asterisk) was used for online gaming due January 31, 2021. Besides, the reference lists of the previous reviews mentioned beforehand were screened.

\section{Study selection and data collection process}

The same authors as above assessed the research first by title and abstract. Then potentially eligible studies were retrieved for full-text screening. The authors of studies with missing data were contacted (Moher et al., 2009) in order to obtain relevant data. Two out of eight authors contacted replied. Whenever duplication was confirmed, only the study with the larger sample size was included (Cosci \& Fava, 2013). Data extraction was done independently by two authors. These authors coded each article in addition to correlation of interest and sample size, by title, authors' name, year of publication, country, personality and gaming measures, internal consistency coefficients, mean of measures, age, gender, data collection method (online/in-person), sample type and mean of other reported psychological measures. Disagreements were resolved over discussion and final consensus between the authors was achieved.

\section{Quality and risk of bias assessment}

Using the Quality of Survey Studies in Psychology (Protogerou \& Hagger, 2020), two authors independently reviewed the eligible studies to assess the quality and the potential risk of bias in reporting. This tool includes twenty items which examine each study from conception to ethics, and the assigned scores are reported from zero to one, the closer to one, the higher the quality and the lower the risk of bias. The two authors' minimum and maximum assigned scores were 0.66 and 0.75 , and the inter-rater reliability was good (ICC $=0.81$ ). Divergences were resolved through consensus.

\section{Data analysis procedures}

This study is being reported based on Borenstein's (2019) guideline to avoid common mistakes in the meta-analyses conduct and reporting. The third version of Comprehensive Meta-Analysis software (CMA-3; Borenstein, Hedges, Higgins, \& Rothstein, 2013) was used to compute pooled effectsizes (ES), and a random-effects model was used to ensure the generalizability of data to comparable studies (Borenstein, Hedges, Higgins, \& Rothstein, 2009). Evans (1996) has suggested cutoff points as follows: $r<0.2=$ very small, $0.2<r<$ $0.4=$ small, $0.4<r<0.6=$ medium, $0.6<r<0.8=$ strong and $r>0.8=$ very strong. These cutoffs were used to interpret the associations observed. However, to ease of interpretation, converting the ESs together is a common practice (Borenstein, 2009), thus ESs were converted into Odds Ratios (ORs). An OR equal to 1 means no association, and values less than one and greater than one can be interpreted as protective factors and risk factors, respectively.

Before pooling the ESs, several sensitivity analyses using the method of "one-study removed" were conducted. And after pooling the ESs, the mixed-effect model was used to test the subgroup differences. For the results, several indices were reported as follows. Given that $I^{2}$ is not an absolute value for the extent of heterogeneity (Borenstein, Higgins, Hedges, \& Rothstein, 2017; Borenstein, 2019), Q and Tau (Johnson, 2021) were reported as an indication of the between-study heterogeneity. Using Borenstein et al. (2017) formula, to cover the limitation of $I^{2}$, the prediction interval (PI) was reported. The PI of -0.58 to +0.30 means that in some populations the ES is low as -0.58 and in some is high as +30 (future studies' correlation will fall in this range).

With regards to publication bias, based on Borenstein's (2019) guideline, the fail-safe N method was not used, so a cumulative analysis was conducted to examine the smallstudy-effect, which studies with smaller sample size and larger ESs can be considered as a reason of publication bias. Also, Egger's regression tests were used, however, these tests can merely indicate the essence of publication bias. Thus, Duval and Tweedie's trimmed procedure was used to determine how ESs would change after controlling the publication bias. Finally, given the number of studies for each continuous moderator was less than the least recommended of $K=10$ (Borenstein et al., 2009; Borenstein, 2019), the meta-regression report was omitted.

\section{RESULTS}

\section{Selection and inclusion of studies}

The plan of election and inclusion of studies as a PRISMA chart is presented in Fig. 1. After discarding duplicated studies, three independent authors screened titles and 


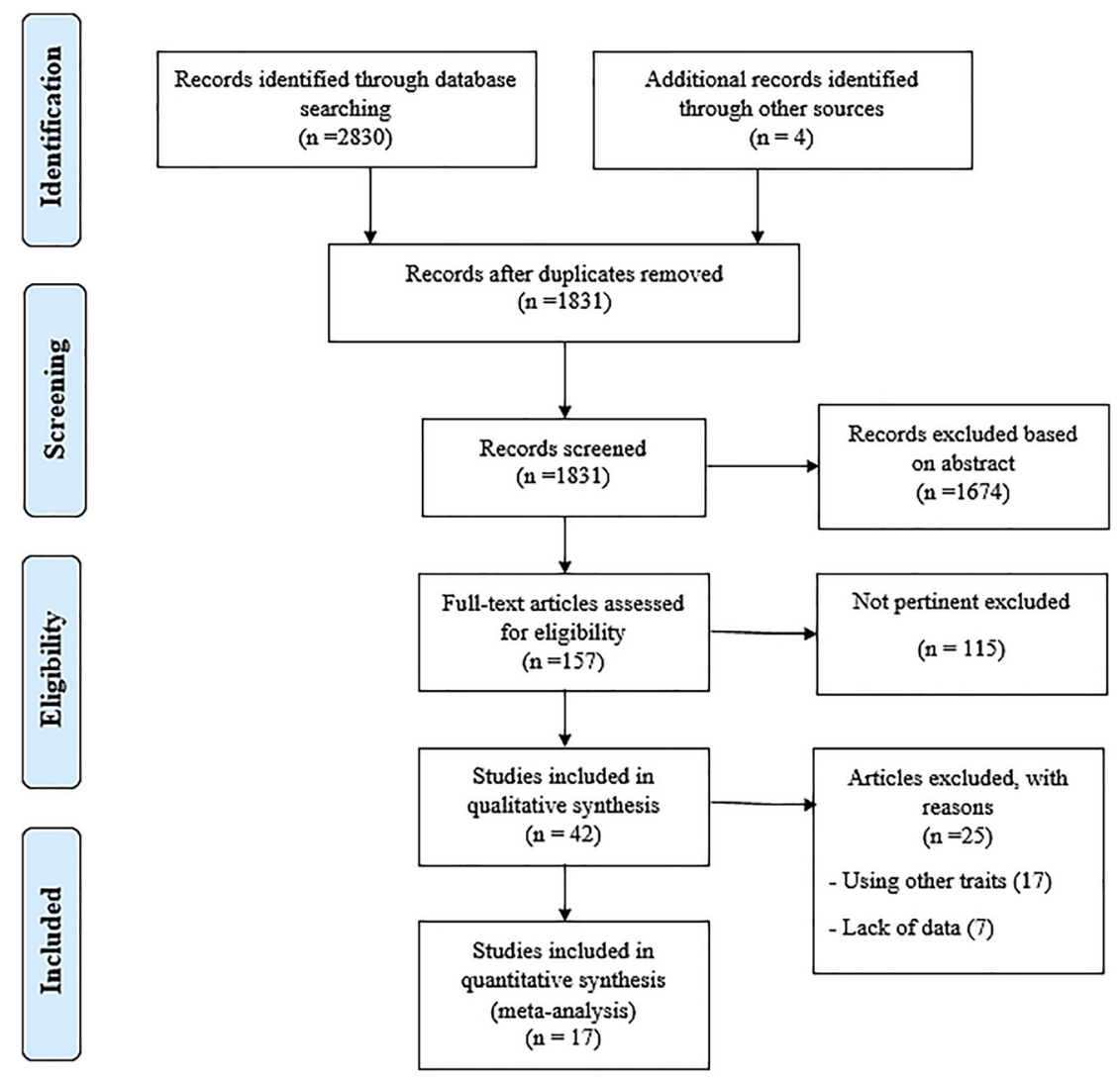

Fig. 1. Diagram for the inclusion of studies

abstracts of the 1831 articles for a primary assessment. From this, 157 articles were retrieved for full-text screening, which left 42 studies qualified for qualitative analysis. Finally, seventeen studies met the inclusion criteria and were entered into the quantitative review.

\section{Quality and sensitivity analysis}

The authors had a consensus to use a criterion of $50 \%$ and higher agreement on each study to be evaluated as an acceptable indicator of good study quality. All of the included studies were in the acceptable range of quality (0.66-0.75). Several sensitivity analyses were undertaken for each subgroup to see if the pooled ESs was robust by differences in the correlation of interest and sample size, year of publication, country, personality and gaming measures, internal consistency coefficients, mean of measures, mean age, gender breakdown, data collection (online/in-person), and sample type. The pooled ESs were not affected by any of the aforementioned variables, except ESs for openness to experience and extraversion which were skewed in one study and were excluded from the computation of ESs for these traits.

\section{Study characteristics}

Overall, 25,634 individuals with a large proportion of young males $\left(M_{\text {age }}=26.55 ; 25.77 \%\right.$ female $)$ comprised the selected studies conducted from 2010 to 2020 . Of this total number, only seven studies had reported the time spent on online gaming $(n=10,794$, mean of the hours per week $=14.9)$. The mean score of online gaming (measured by for example the Gaming Addiction Scale (GAS; Lemmens, Valkenburg, \& Peter, 2009) from eight studies $(n=5,860)$ was 1.28 , calculated from a scale of one to ten. Also, the reported mean scores for trait personalities in a scale of one to ten were as follows: agreeableness $(K=8, n=12,151$, mean $=3.415)$, conscientiousness $(K=7, n=11,813$, mean $=5.275)$, extraversion $(K=10, n=14,105$, mean $=6.251)$, neuroticism $(K=13, n=20,890$, mean $=5.82)$, and openness to experience $(K=7, n=11,813$, mean $=4.84)$.

The geographic distribution of the studies saw $64.7 \%$ coming from Europe $(k=11$; Germany, Norway, Spain, United Kingdom, and Switzerland), 23.52\% from the United States $(k=4)$, and $11.76 \%$ from Asia ( $k=2$; China). Also, with regards to the data collection, $41.17 \%$ and $52.94 \%$ preferred online survey and paper-pencil method, respectively.

Online gaming was examined by questionnaires such as the Internet Online Gaming Scale (IGDS, Pontes, Kiraly, Demetrovics, \& Griffiths, 2014), the Gaming Addiction Scale (GAS), and the Problematic Online Gaming Questionnaire (POGQ, Demetrovics et al., 2012). The average internal consistency of gaming measures was 0.87 which is acceptable. Most studies used Big Five personality traits-based measures to examine the traits of interest, two used the extraversion and neuroticism subscales of short-form revised Eysenck Personality Questionnaire (EPQ-RS; Barrett, Petrides, Eysenck, \& Eysenck, 
1998; Eysenck, Eysenck, \& Barrett, 1985), and two used the Zuckerman-Kuhlman Personality Questionnaire (ZKPQ; Aluja et al., 2006) and short version of Personality Inventory for DSM-5 (PID-5-BF; Krueger, Derriger, Markon, Watson, \& Skodol, 2015). The average internal consistency of personality trait measures was 0.65 which is acceptable. Please see Table 1 for the characteristics of included studies and the Table 2 for the associations between the Big Five personality traits and online gaming.

\section{The Big Five personality traits and online gaming}

Agreeableness. Agreeableness was shown to have a very small association with online gaming $(r=-0.19,95 \% C I$ -0.25 to -0.12 ), as can be seen by the ESs forest plot depicted in Fig. 2. Based on Table 4 and the PI values, it can be said that in some populations, the ESs is as high as -0.40 and in some as trivial as 0.040 .

Extraversion. As the ESs forest plot in Fig. 3 depicts, extraversion has a small association with online gaming ( $r=$ $-0.13,95 \%$ CI -0.16 to -0.09$)$. The PI values in Table 4 indicate that in some populations, the ESs is as high as -0.23 and in some as trivial as -0.01 .

Openness to experience. Unexpectedly, the mean ESs forest plot in Fig. 4 depicts a very small association between openness to experience and online gaming $(r=-0.05,95 \%$ $C I-0.08$ to -0.02$)$. However, PI values in Table 4 indicate that in some populations, the ESs is as high as -0.13 and in some as trivial as 0.037 .

Neuroticism. The forest plot depicted in Fig. 5 shows a small association of neuroticism with online gaming $(r=$ $0.21,95 \%$ CI 0.16-0.26), and based on PI values in Table 4, in some populations, the ESs is as high as 0.38 and in some as trivial as 0.021 .

Conscientiousness. Conscientiousness also shows a small association with online gaming $(r=-0.27,95 \% C I-0.31$ to $-0.23)$, depicted in the forest plot, Fig. 6. Moreover, based on PI values in Table 4, in some populations, the ESs is as high as -0.39 and in some as low as -0.13 .

\section{Moderator analysis}

Given the impossibility of conducting a meta-regression, categorical moderator analysis was conducted to determine the possible reason for heterogeneity. The results are shown in Table 5.

Gamers versus general population. The omnibus test in Table 5 shows no significant differences between gamers versus the general population in the relationship of Big Five personality traits and online gaming.

Online versus in-person. Regarding data collection, there were also no significant differences in the relationship between the Big Five personality traits and online gaming.
Younger versus elder. Comparing the ESs based on mean age greater than twenty years old and less than or equal to twenty years old were no significant differences in the relationship between the Big Five personality traits and online gaming were observed.

Casual versus hardcore gamers. Based on time spent gaming, ESs of the relationship of Big Five personality traits and online gaming were not significantly different when comparing casual gaming (less than $15 \mathrm{~h}$ per week), hardcore gaming (more than $15 \mathrm{~h}$ per week), and studies which did not report gaming time.

High versus low in a trait. On a scale of one to ten, scores greater than five and lower than five were categorized as low and high on a given trait. The omnibus test shows no significant differences in the ESs in the relationship of the Big Five personality traits with online gaming, except for neuroticism for which the strength of the relationship with online gaming was higher among individuals with scores greater than five and vice versa.

\section{Publication bias}

Publication bias was first appraised for small-study-effect which shows no evidence of bias in this regard. Then, we proceeded by testing Egger's regression. The test was significant for conscientiousness $(b=-0.19, P=0.04)$, showing a potential publication bias. Therefore, Duval and Tweedie's procedure was performed to compute adjusted ESs. As Table 3 suggests there is no evidence of publication bias.

\section{Pairwise omnibus test: looking for fundamental domain}

To see which of the Big Five personality traits are protective or risk factors of online gaming, the ESs were converted to continuous OR. Agreeableness $(O R=0.494[0.386,0.633])$, openness to experience $(O R=0.834[0.741,0.939])$ and extraversion $(O R=0.628[0.549,0.719])$ were protective factors for online gaming in some populations, but conscientiousness $(O R=0.367[0.312,0.430])$ in all populations decreased the odds of online gaming by 64 percent. Also, neuroticism was a risk factor for online gaming ( $\mathrm{OR}=$ 2.181), which means that with increases in neuroticism, the odds of online gaming increase twofold. In addition, high neuroticism (scores greater than five) increased the odds of online gaming by $2.859[2.183,3.745]$, almost three times. Low neuroticism (scores lower than five) increases the odds of online gaming by 1.893 [1.498, 2.393], nearly two times, which makes it a fundamental trait in addition to conscientiousness.

\section{DISCUSSION}

The key question inspiring this systematic review and metaanalysis was which of the Big Five personality traits would 
Table 1. Characteristics for the included studies

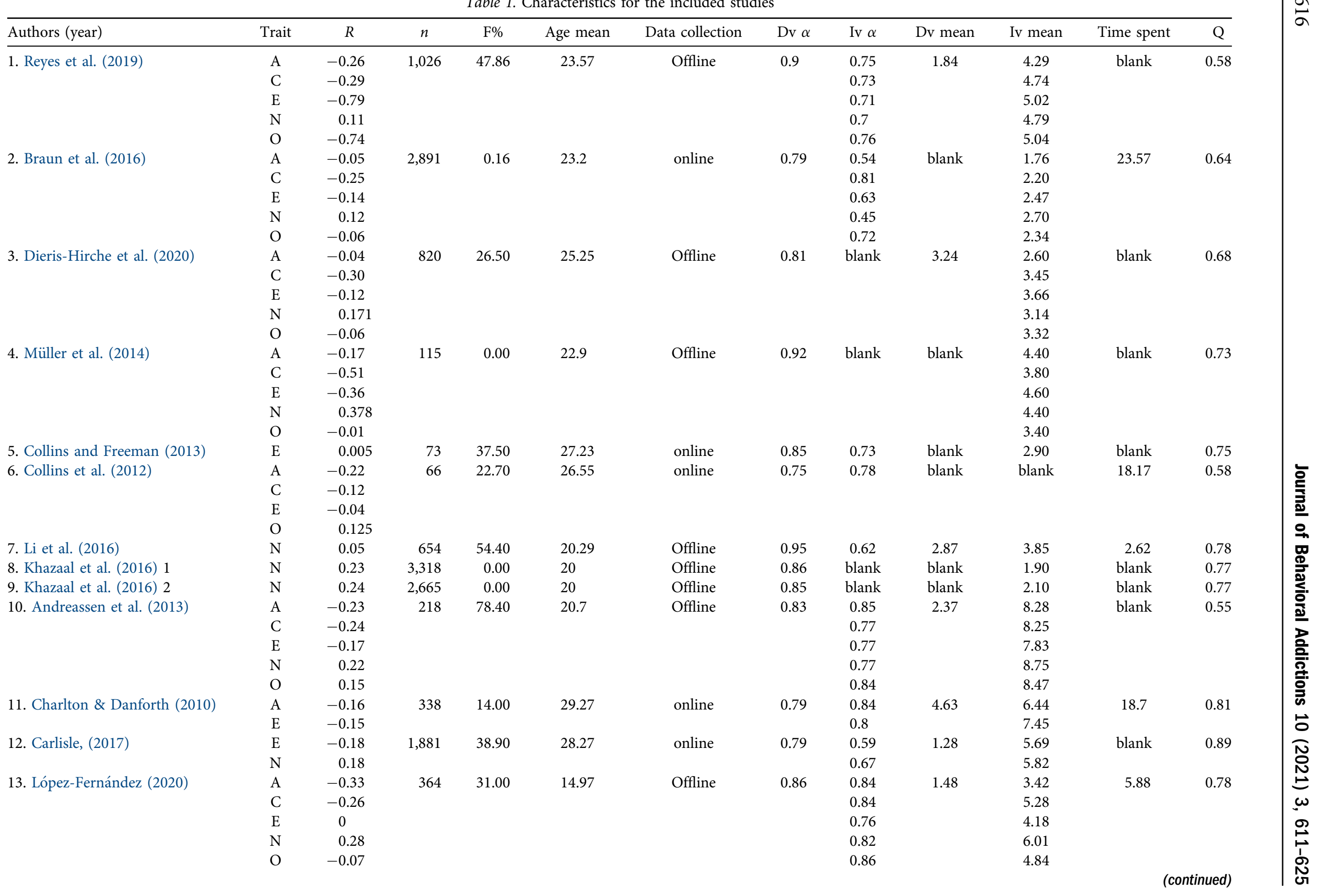




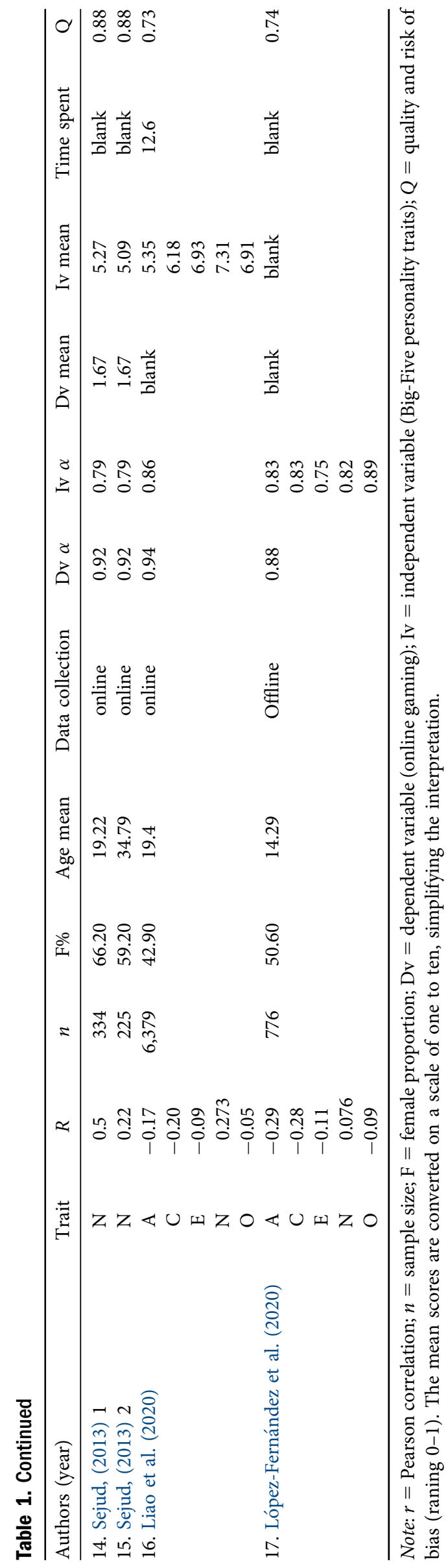

best predict online gaming? Adjusted ESs in Table 3 show openness to experience had the lowest mean association with online gaming. The highest ESs, still not significantly different from the rest of the traits (except for neuroticism), belonged to conscientiousness. Given that personality traits can be evaluated as protective (Kuss, Van Rooij, Shorter, Griffiths, \& van de Mheen, 2013), conscientiousness in any population appears to have a protective role against online gaming, but neuroticism is a risk factor for online gaming for some but not all individuals, as indexed by PI.

\section{Agreeableness and online gaming}

The observed trivial effect on this association in some populations and small effect in others may suggest the importance of video game genres (Wittek et al., 2016). Collaboration is essential in some genres (particularly MMORPGs); thus, individuals with high or low agreeableness will act differently in this situation. Those displaying high levels of this trait tend to avoid competition (Şalvarlı \& Griffiths, 2019), while those displaying low levels of this trait have a strong desire to compete (Müller et al., 2014). As a result, when the genres needed cooperation, gamers with low agreeableness levels may show trivial effects.

\section{Extraversion and online gaming}

The observed trivial effect on this association might, again, be explained by game genres. Both introverted and extraverted individuals may be involved in gaming; however, extraverted individuals may also participate in the virtual environment to improve social enhancement, and some introverted people may not be able to maintain being involved in some games because the games require a friendly and cooperative attitude (Müller et al., 2014; Şalvarlı \& Griffiths, 2019).

\section{Openness to experience and online gaming}

Among the protective factors against online gaming, the PI confidence interval indicates the least low limit. This finding may be explained by the tendency of individuals high on this trait to search both real and virtual life environments to fulfill their curiosity and enthusiasm (Kayiş et al., 2016). They may choose to experience real-life events over virtual ones, making this trait less pertinent to online gaming compared to all the other Big Five personality traits.

\section{Neuroticism and online gaming}

Şalvarlı and Griffiths (2019) found that there is either a positive relationship between gaming disorder and neuroticism or no relationship at all. This is consistent with the current study's findings. This observation can be attributed to the fact that some neurotic individuals are un-confident and may use gaming to inhibit or prevent negative feelings (Mehroof \& Griffiths, 2010) and escape their problems (Wittek et al., 2016). On the other hand, some neurotic individuals may not be able to concentrate well due to a loss of emotional balance (Wang et al., 2015). 
Table 2. Big Five personality traits and online gaming

\begin{tabular}{|c|c|c|c|c|c|c|c|c|c|c|c|}
\hline \multirow[b]{2}{*}{ Domain } & \multicolumn{5}{|c|}{ Effect-sizes and 95\% interval } & \multicolumn{3}{|c|}{ Heterogeneity } & \multicolumn{2}{|c|}{ Prediction interval } & \multirow{2}{*}{$\begin{array}{l}\text { Omnibus test } \\
Q(d f) P \text {-value }\end{array}$} \\
\hline & K & $n$ & $r$ & $\mathrm{Ll}$ & Ul & $Q$-value $(d f)$ & $I^{2}$ & $T^{2}$ & $\mathrm{Ll}$ & Ul & \\
\hline A & 10 & 12,993 & -0.19 & -0.25 & -0.12 & $89.197(9)$ & 89.91 & 0.009 & -0.40 & 0.040 & 232.58 (4) $P=0.001$ \\
\hline $\mathrm{C}$ & 9 & 12,655 & -0.27 & -0.31 & -0.23 & $29.42(8)$ & 72.81 & 0.003 & -0.39 & -0.13 & \\
\hline $\mathrm{O}$ & 8 & 11,629 & -0.05 & -0.08 & -0.02 & $12.68(7)$ & 44.80 & 0.001 & -0.13 & 0.037 & \\
\hline $\mathrm{E}$ & 11 & 13,921 & -0.13 & -0.16 & -0.09 & $28.90(10)$ & 65.40 & 0.002 & -0.23 & -0.01 & \\
\hline $\mathrm{N}$ & 14 & 21,666 & 0.21 & 0.16 & 0.26 & 146.30 & 91.11 & 0.007 & 0.021 & 0.38 & \\
\hline
\end{tabular}

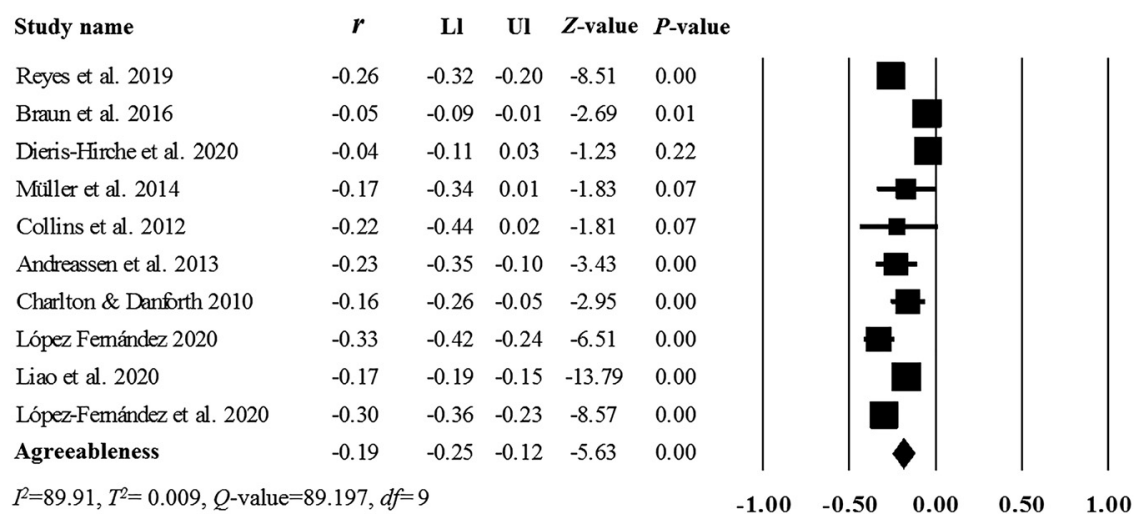

Fig. 2. Forest plot for the association of online gaming and agreeableness, by $95 \% \mathrm{CI}$

Table 3. Adjusted effect-sizes for publication bias bases on Duval and Tweedie's trim and fill method

\begin{tabular}{|c|c|c|c|c|c|c|c|c|c|c|}
\hline \multirow[b]{2}{*}{ Domain } & \multicolumn{5}{|c|}{ Egger's regression test of publication bias } & \multicolumn{5}{|c|}{ Adjusted effect-sizes } \\
\hline & $b$ & $S E$ & $\mathrm{Ll}$ to $\mathrm{Ul}$ & $t$-value $(d f)$ & $P$-value ${ }^{*}$ & St & $r$ & $\mathrm{Ll}$ & $\mathrm{Ul}$ & $Q$-value \\
\hline A & -0.147 & 1.733 & -5.47 to 2.52 & $0.84(8)$ & 0.210 & 1 & -0.17 & -0.23 & -0.11 & 97.107 \\
\hline $\mathrm{C}$ & -0.190 & 0.928 & -4.09 to 0.296 & $2.04(7)$ & 0.04 & - & -0.26 & -0.30 & -0.22 & 29.41 \\
\hline $\mathrm{O}$ & 1.066 & 0.726 & -0.71 to 2.84 & $1.46(6)$ & 0.09 & 2 & -0.06 & -0.10 & -0.02 & 24.85 \\
\hline E & -0.503 & 0.882 & -2.49 to 1.49 & $0.57(9)$ & 0.291 & - & -0.12 & -0.16 & -0.09 & 28.90 \\
\hline $\mathrm{N}$ & -0.651 & 1.866 & -4.71 to 3.41 & $0.34(12)$ & 0.366 & - & 0.21 & 0.16 & 0.25 & 146.29 \\
\hline
\end{tabular}

St $=$ Studies trimmed; ${ }^{\star}=$ One-tailed.

Table 4. Pairwise omnibus moderator analyses comparing gamers versus general population

\begin{tabular}{|c|c|c|c|c|c|c|c|c|}
\hline \multirow[b]{2}{*}{ Domain } & \multirow[b]{2}{*}{ Participants } & \multicolumn{5}{|c|}{ Effect-sizes and 95\% interval } & \multirow{2}{*}{$\begin{array}{c}\text { Omnibus test } \\
Q(d f)\end{array}$} & \multirow[b]{2}{*}{$P$-value } \\
\hline & & $K$ & $n$ & $r$ & $\mathrm{Ll}$ & $\mathrm{Ul}$ & & \\
\hline \multirow[t]{2}{*}{ Agreeableness } & Gamers & 7 & 9,818 & -0.21 & -0.28 & -0.14 & \multirow[t]{2}{*}{0.88 (1) } & \multirow[t]{2}{*}{0.35} \\
\hline & General population & 3 & 3,175 & -0.14 & -0.26 & -0.02 & & \\
\hline \multirow[t]{2}{*}{ Conscientiousness } & Gamers & 6 & 9,480 & -0.29 & -0.34 & -0.23 & \multirow[t]{2}{*}{$1.01(1)$} & \multirow[t]{2}{*}{0.31} \\
\hline & General population & 3 & 3,175 & -0.23 & -0.32 & -0.14 & & \\
\hline \multirow[t]{2}{*}{ Openness to Experience } & Gamers & 5 & 9,480 & -0.07 & -0.11 & -0.02 & \multirow[t]{2}{*}{$2.172(1)$} & \multirow[t]{2}{*}{0.14} \\
\hline & General population & 3 & 3,175 & -0.002 & -0.072 & 0.069 & & \\
\hline \multirow[t]{2}{*}{ Extraversion } & Gamers & 8 & 10,746 & -0.12 & -0.17 & -0.08 & \multirow[t]{2}{*}{$0.07(1)$} & \multirow[t]{2}{*}{0.79} \\
\hline & General population & 3 & 3,175 & -0.14 & -0.22 & -0.05 & & \\
\hline \multirow[t]{2}{*}{ Neuroticism } & Gamers & 8 & 12,015 & 0.18 & 0.11 & 0.25 & \multirow[t]{2}{*}{$1.82(1)$} & \multirow[t]{2}{*}{0.18} \\
\hline & General population & 6 & 9,651 & 0.25 & 0.17 & 0.33 & & \\
\hline
\end{tabular}




\begin{tabular}{|c|c|c|c|c|c|}
\hline Study name & $\boldsymbol{r}$ & Ll & UI & $Z$-value & $P$-val \\
\hline Braun et al. 2016 & -0.14 & -0.18 & -0.10 & -7.57 & 0.00 \\
\hline Dieris-Hirche et al. 2020 & -0.13 & -0.19 & -0.06 & -3.68 & 0.00 \\
\hline Müller et al. 2014 & -0.36 & -0.51 & -0.19 & -4.01 & 0.00 \\
\hline Collins \& Freeman 2013 & 0.01 & -0.23 & 0.23 & 0.04 & 0.97 \\
\hline Collins et al. 2012 & -0.04 & -0.28 & 0.20 & -0.33 & 0.74 \\
\hline Andreassen et al. 2013 & -0.17 & -0.30 & -0.04 & -2.52 & 0.01 \\
\hline Charlton \& Danforth 2010 & -0.15 & -0.25 & -0.04 & -2.77 & 0.01 \\
\hline Carlisle, 2017 & -0.18 & -0.22 & -0.14 & -7.89 & 0.00 \\
\hline López Femández 2020 & 0.00 & -0.10 & 0.10 & 0.00 & 1.00 \\
\hline Liao et al. 2020 & -0.09 & -0.12 & -0.07 & -7.29 & 0.00 \\
\hline López-Femández et al. 2020 & -0.12 & -0.19 & -0.05 & -3.30 & 0.00 \\
\hline Extraversion & -0.13 & -0.16 & -0.09 & -6.76 & 0.00 \\
\hline
\end{tabular}

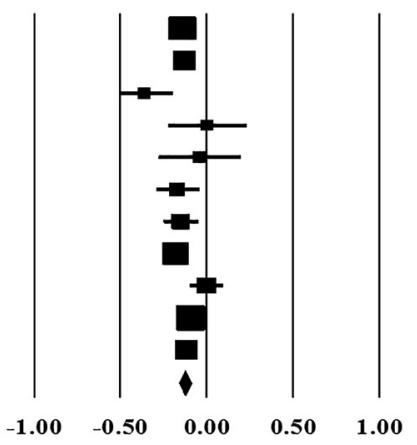

Fig. 3. Forest plot for the association of online gaming and extraversion, by $95 \% \mathrm{CI}$

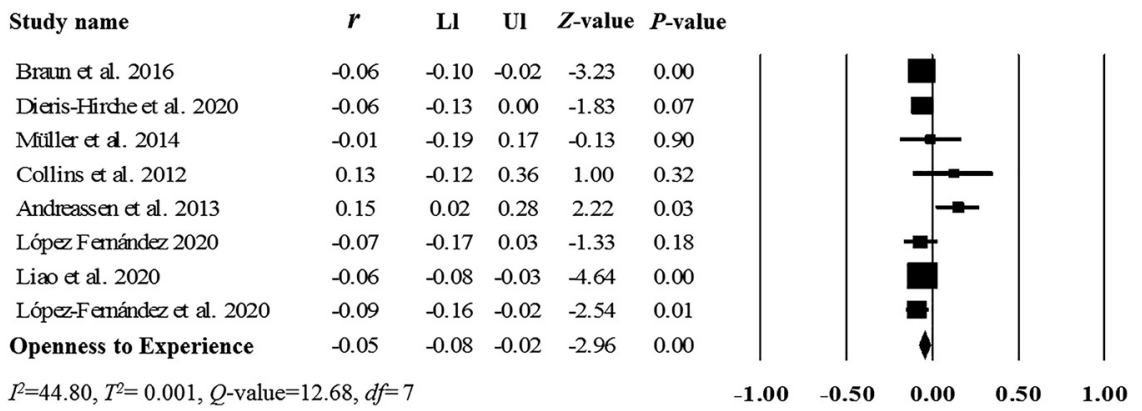

Fig. 4. Forest plot for the association of online gaming and openness to experience, by $95 \%$ CI

Study name

Reyes et al. 2019

Braun et al. 2016

Dieris-Hirche et al. 2020

Miiller et al. 2014

Li et al. 2016

kharaal et al. 2016 a

khazaal et al. $2016 \mathrm{~b}$

Andreassen et al. 2013

Carlisle, 2017

López Fernández 2020

Sejud, 2013 a

Sejud, 2013 b

Liao et al. 2020

López-Femández et al. 2020

Neuroticism

$I^{2}=91.11, T^{2}=0.007, Q$-value $=146.30, d f=13$

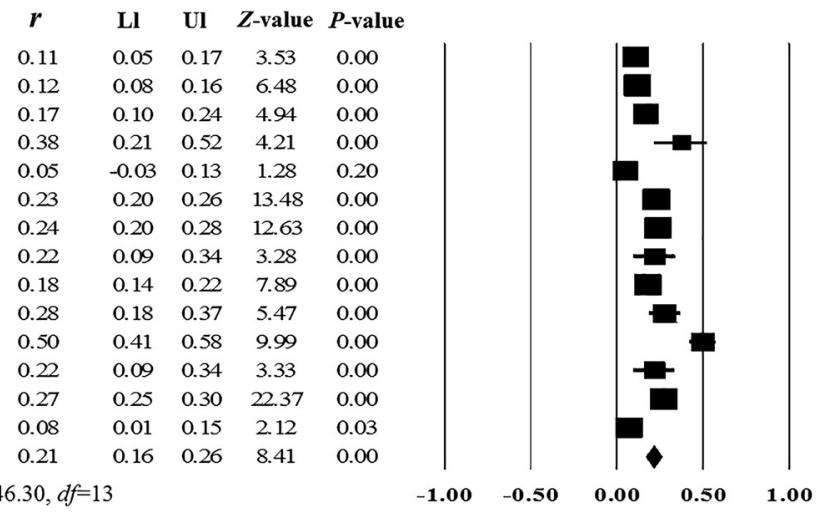

Fig. 5. Forest plot for the association of online gaming and neuroticism, by $95 \% \mathrm{CI}$

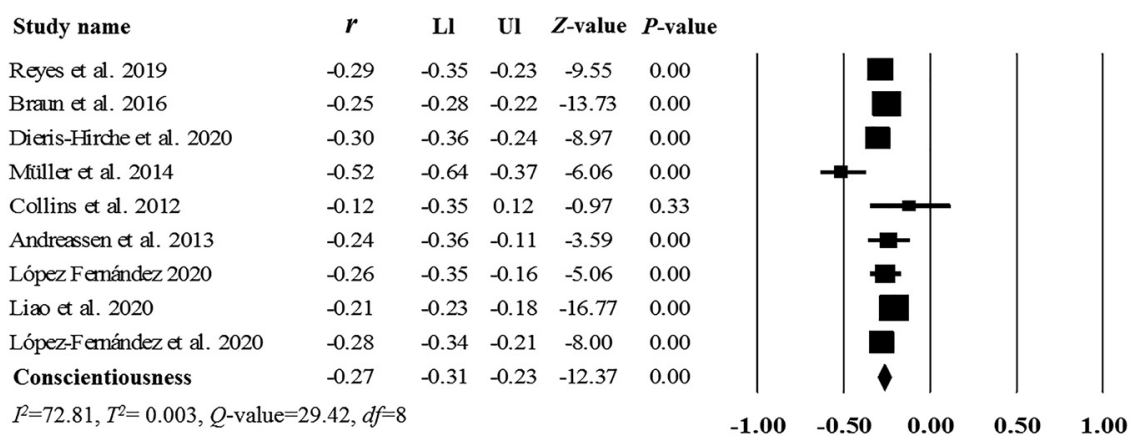

Fig. 6. Forest plot for the association of online gaming and conscientiousness, by $95 \% \mathrm{CI}$ 
Table 5. Results for the categorical moderator analysis

\begin{tabular}{|c|c|c|c|c|c|c|c|}
\hline Moderator & $k$ & $R$ & $95 \% \mathrm{CI}$ & $Z(P$-value $)$ & $\mathrm{Q}(d f)$ & $I^{2}(P$-value $)$ & $T^{2}$ \\
\hline \multicolumn{8}{|c|}{ Agreeableness } \\
\hline \multicolumn{8}{|c|}{ Data Collection $(Q=1.758, d f=1, P=0.185)$} \\
\hline Online & 4 & -0.14 & {$[-0.24,-0.03]$} & $-2.57(0.01)$ & $30.67(3)$ & $90.22(0.01)$ & 0.006 \\
\hline In-person & 6 & -0.23 & {$[-0.31,-0.14]$} & $-5.24(0.01)$ & $39.50(5)$ & $87.34(0.01)$ & 0.014 \\
\hline \multicolumn{8}{|c|}{ Youngers versus elders $(Q=2.810, d f=1, P=0.094)$} \\
\hline Age $>20$ years & 6 & -0.14 & {$[-0.23,-0.05]$} & $-3.04(0.01)$ & $40.92(5)$ & $87.78(0.01)$ & 0.011 \\
\hline Age $\leq 20$ years & 4 & -0.26 & {$[-0.35,-0.15]$} & $-4.85(0.01)$ & $21.33(3)$ & $85.93(0.01)$ & 0.008 \\
\hline \multicolumn{8}{|c|}{ Casual versus hardcore gamers $(Q=1.390, d f=2, P=0.499)$} \\
\hline Unknown & 5 & -0.20 & {$[-0.30,-0.10]$} & $-3.79(0.01)$ & $33.77(4)$ & $88.15(0.01)$ & 0.014 \\
\hline Less than $15 \mathrm{~h}$ & 2 & -0.24 & {$[-0.39,-0.09]$} & $-3.06(0.01)$ & $9.89(1)$ & $89.89(0.01)$ & 0.013 \\
\hline Greater than $15 \mathrm{~h}$ & 3 & -0.12 & {$[-0.26,0.02]$} & $-1.70(0.09)$ & $5.43(2)$ & $63.16(0.07)$ & 0.005 \\
\hline \multicolumn{8}{|c|}{ Level of Trait $(Q=0.036, d f=1, P=0.850)$} \\
\hline Higher than 5 & 3 & -0.18 & {$[-0.31,-0.05]$} & $-2.65(0.01)$ & $0.84(2)$ & $0.00(0.66)$ & 0.000 \\
\hline Lower than 5 & 5 & -0.17 & {$[-0.27,-0.06]$} & $-3.11(0.01)$ & $58.89(4)$ & $93.21(0.01)$ & 0.017 \\
\hline
\end{tabular}

Data Collection $(Q=0.00, d f=1, P=0.991)$

\begin{tabular}{|c|c|c|c|c|c|c|c|}
\hline Online & 6 & -0.13 & {$[-0.18,-0.08]$} & $-4.89(0.01)$ & $15.54(5)$ & $67.83(0.01)$ & 0.001 \\
\hline In-person & 5 & -0.13 & {$[-0.19,-0.07]$} & $-4.07(0.01)$ & $13.36(4)$ & $70.05(0.01)$ & 0.006 \\
\hline \multicolumn{8}{|c|}{ Youngers versus elders $(Q=3.819, d f=1, P=0.051)$} \\
\hline Age $>20$ years & 7 & -0.15 & {$[-0.19,-0.11]$} & $-7.39(0.01)$ & $10.73(6)$ & $44.07(0.10)$ & 0.001 \\
\hline Age $\leq 20$ years & 4 & -0.09 & {$[-0.14,-0.04]$} & $-3.82(0.01)$ & $4.97(3)$ & $39.62(0.17)$ & 0.001 \\
\hline \multicolumn{8}{|c|}{ Casual versus hardcore gamers $(Q=4.75, d f=2, P=0.09)$} \\
\hline Unknown & 6 & -0.16 & {$[-0.20,-0.11]$} & $-6.24(0.01)$ & $10.35(5)$ & $51.70(0.07)$ & 0.002 \\
\hline Less than $15 \mathrm{~h}$ & 2 & -0.07 & {$[-0.13,0.00]$} & $-1.93(0.05)$ & $2.84(1)$ & $64.85(0.09)$ & 0.003 \\
\hline Greater than $15 \mathrm{~h}$ & 3 & -0.14 & {$[-0.20,-0.07]$} & $-3.96(0.01)$ & $0.65(2)$ & $0.00(0.72)$ & 0.000 \\
\hline \multicolumn{8}{|c|}{ Level of Trait $(Q=0.168, d f=1, P=0.682)$} \\
\hline Higher than 5 & 4 & -0.14 & {$[-0.21,-0.07]$} & $-4.03(0.01)$ & $13.15(3)$ & $77.19(0.01)$ & 0.003 \\
\hline Lower than 5 & 5 & -0.12 & {$[-0.19,-0.05]$} & $-3.38(0.01)$ & $14.68(4)$ & $72.75(0.01)$ & 0.005 \\
\hline
\end{tabular}

Openness to Experience

Data Collection $(Q=0.272, d f=1, P=0.602)$

\begin{tabular}{|c|c|c|c|c|c|c|c|}
\hline Online & 3 & -0.04 & {$[-0.08,0.01]$} & $-1.49(0.14)$ & $9.26(2)$ & $78.40(0.01)$ & 0.002 \\
\hline In-person & 3 & -0.06 & {$[-0.13,0.01]$} & $-1.66(0.10)$ & $0.31(2)$ & $0.00(0.86)$ & 0.000 \\
\hline \multicolumn{8}{|c|}{ Youngers versus elders $(Q=0.45, d f=1, P=0.499)$} \\
\hline Age $>20$ years & 3 & -0.06 & {$[-0.13,0.01]$} & $-1.57(0.12)$ & $0.27(2)$ & $0.00(0.87)$ & 0.000 \\
\hline Age $\leq 20$ years & 3 & -0.02 & {$[-0.09,0.05]$} & $-0.61(0.54)$ & $9.22(2)$ & $78.32(0.01)$ & 0.007 \\
\hline \multicolumn{8}{|c|}{ Casual versus hardcore gamers $(Q=0.43, d f=2, P=0.817)$} \\
\hline Unknown & 4 & -0.02 & {$[-0.10,0.06]$} & $-0.58(0.56)$ & $10.33(3)$ & $70.96(0.02)$ & 0.006 \\
\hline Less than $15 \mathrm{~h}$ & 2 & -0.06 & {$[-0.16,0.03]$} & $-1.27(0.20)$ & $0.05(1)$ & $0.00(0.82)$ & 0.000 \\
\hline Greater than $15 \mathrm{~h}$ & 2 & -0.03 & {$[-0.14,0.08]$} & $-0.49(0.62)$ & $2.13(1)$ & $52.98(0.14)$ & 0.009 \\
\hline \multicolumn{8}{|c|}{ Level of Trait $(Q=1.06, d f=1, P=0.301)$} \\
\hline Higher than 5 & 2 & -0.004 & {$[-0.09,0.08]$} & $-0.09(0.93)$ & $9.10(1)$ & $89.01(0.01)$ & 0.019 \\
\hline Lower than 5 & 4 & -0.06 & {$[-0.12,0.00]$} & $-1.83(0.07)$ & $0.31(3)$ & $0.00(0.96)$ & 0.000 \\
\hline
\end{tabular}

\section{Neuroticism}

Data Collection $(Q=1.64, d f=1, P=0.200)$

\begin{tabular}{|c|c|c|c|c|c|c|c|}
\hline Online & 5 & 0.25 & {$[0.17,0.33]$} & $5.83(0.01)$ & $88.64(4)$ & $95.49(0.00)$ & 0.012 \\
\hline In-person & 9 & 0.19 & {$[0.12,0.25]$} & $5.50(0.01)$ & $51.77(8)$ & $84.55(0.00)$ & 0.006 \\
\hline \multicolumn{8}{|c|}{ Youngers versus elders $(Q=1.61, d f=1, P=0.204)$} \\
\hline Age $>20$ years & 6 & 0.18 & {$[0.11,0.24]$} & $4.98(0.00)$ & $14.52(5)$ & $65.56(0.01)$ & 0.002 \\
\hline Age $\leq 20$ years & 8 & 0.23 & {$[0.18,0.29]$} & $7.90(0.00)$ & $86.32(7)$ & $91.89(0.01)$ & 0.007 \\
\hline
\end{tabular}

Casual versus hardcore gamers $(Q=1.20, d f=2, P=0.548)$ 
Table 5. Continued

\begin{tabular}{lccccrrr}
\hline Moderator & $k$ & $R$ & $95 \%$ CI & $Z(P$-value $)$ & $\mathrm{Q}(d f)$ & $I^{2}(P$-value $)$ & $T^{2}$ \\
\hline Unknown & 10 & 0.23 & {$[0.16,0.28]$} & $7.02(0.00)$ & $73.84(9)$ & $87.81(0.01)$ & 0.007 \\
Less than 15 $\mathrm{h}$ & 3 & 0.20 & {$[0.09,0.31]$} & $3.60(0.00)$ & $31.55(2)$ & $93.66(0.01)$ & 0.016 \\
Greater than $15 \mathrm{~h}$ & 1 & 0.12 & {$[-0.06,0.30]$} & $1.28(0.20)$ & $0.00(0)$ & $0.00(1.00)$ & 0.000 \\
Level of Trait $(\boldsymbol{Q}=\mathbf{5 . 0 5}, \boldsymbol{d f}=\mathbf{1 , ~} \boldsymbol{P}=\mathbf{0 . 0 2})$ & & & & & \\
Higher than 5 & 6 & 0.28 & {$[0.21,0.35]$} & $7.70(0.00)$ & $42.02(5)$ & $88.10(0.01)$ & 0.008 \\
Lower than 5 & 7 & 0.17 & {$[0.11,0.24]$} & $5.38(0.00)$ & $52.23(6)$ & $88.51(0.01)$ & 0.005
\end{tabular}

Conscientiousness

Data Collection $(Q=5.07, d f=1, P=0.02)$

\begin{tabular}{|c|c|c|c|c|c|c|c|}
\hline Online & 3 & -0.22 & {$[-0.27,-018]$} & $-8.88(0.00)$ & $4.74(2)$ & $57.79(0.09)$ & 0.001 \\
\hline In-person & 6 & -0.30 & {$[-0.34,-0.25]$} & $-13.12(0.00)$ & $9.63(5)$ & $48.11(0.09)$ & 0.002 \\
\hline \multicolumn{8}{|c|}{ Youngers versus elders $(Q=1.55, d f=1, P=0.212)$} \\
\hline Age $>20$ years & 5 & -0.29 & {$[-0.35,-0.24]$} & $-9.97(0.00)$ & $14.16(4)$ & $71.76(0.01)$ & 0.004 \\
\hline Age $\leq 20$ years & 4 & -0.24 & {$[-0.30,-0.18]$} & $-7.86(0.00)$ & $5.06(3)$ & $40.70(0.17)$ & 0.001 \\
\hline \multicolumn{8}{|c|}{ Casual versus hardcore gamers $(Q=4.15, d f=2, P=0.125)$} \\
\hline Unknown & 5 & -0.30 & {$[-0.35,-0.25]$} & $-11.14(0.00)$ & $9.11(4)$ & $56.10(0.06)$ & 0.002 \\
\hline Less than $15 \mathrm{~h}$ & 2 & -0.22 & {$[-0.29,-0.15]$} & $-6.14(0.00)$ & $1.07(1)$ & $6.91(0.30)$ & 0.00 \\
\hline Greater than $15 \mathrm{~h}$ & 2 & -0.24 & {$[-0.32,-0.15]$} & $-5.52(0.00)$ & $1.09(1)$ & $8.04(0.30)$ & 0.001 \\
\hline \multicolumn{8}{|c|}{ Level of Trait $(Q=2.71, d f=1, P=0.09)$} \\
\hline Higher than 5 & 3 & -0.23 & {$[-0.29,-0.16]$} & $-6.32(0.00)$ & $1.28(2)$ & $0.00(0.53)$ & 0.000 \\
\hline Lower than 5 & 4 & -0.30 & {$[-0.35,-0.24]$} & $-10.07(0.00)$ & $12.59(3)$ & $76.17(0.01)$ & $0.003 w$ \\
\hline
\end{tabular}

\section{Conscientiousness and online gaming}

Low-conscientious individuals are characterized as being less persistent in pursuing personal goals, unstructured, and having a hard time organizing their day-to-day life (Müller et al., 2014). As a way of escaping, gamers with these characteristics may be more likely to develop problematic gaming behaviours by losing themselves in virtual settings and not paying attention to everyday life duties (Müller et al., 2014). On the other hand, individuals with high conscientiousness are more organized and highly involved in 'real life' in search of achieving personal goals. It follows, that their values and engagement in 'real life' may act as a protective factor against online gaming.

\section{Limitations and future directions}

This review's strength is that it was done according to existing standards (Borenstein, 2019), but a meta-analysis cannot contain data that has not been published in the included studies; thus, it has the following limitations. First, the included studies did not report the totality of variables (such as motivation to game, time spent gaming, genres of games, cognition) that could be used in moderator analysis, resulting in the omitted meta-regression.

Second, the data's generalizability is restricted to Europe (65\% of studies), the United States (24\% of studies), and males due to their over-representation (female $=25 \%$ ), and young adults $\left(\right.$ Age $\left._{\text {Mean }}=26.55\right)$. Third, our endeavor was limited to the Big Five personality traits and inclusion of only English publications due to lack of resources. Finally, the conclusions from our findings should be tempered by the observational and cross-sectional nature of the studies reviewed.
Overall, there are several suggestions for further research to fill the gaps in the literature. First, given the importance of neuroticism and conscientiousness in online gaming, dissecting each trait's six facets could help better understand their role in both online gaming and Internet Gaming Disorder. Plus, given that neuroticism was not a significant factor among some populations as indexed by prediction intervals, future studies might want to explore that among which types of gamers, neuroticism is not a determining factor. Moreover, given that there were non-significant differences between gamers and the general population, future research might use extreme samples (diagnosed with gaming disorder vs. regular gamers) to see if whether the differences are significant or not; thus, given the extant literature, a firm conclusion cannot be drawn yet.

Furthermore, future research may consider shedding light on the Big Five personality traits in relation to the underlying shared variance embedded within the frame of two personality meta-traits: stability (conscientiousness, neuroticism, and agreeableness) and plasticity (extraversion and openness to experience). Plasticity is related to an individual's fundamental need to absorb innovative experiences from the environment (engagement). Stability is related to the need to maintain a constant combination of behavioral and psychological activity (satiety and restraint of behavior). These meta-traits are also related to the serotonergic and dopaminergic neurotransmitter systems' activity, respectively (DeYoung, Peterson, \& Higgins, 2002). For more details on the big-two personality meta-traits, see Hirsh, DeYoung, and Peterson (2009) and DeYoung (2006). Second, comparing individuals on high and low levels of each trait may shed light on some moderators and 
covariates that can explain these disparities of ESs. Given that conscientiousness is a protective factor against online gaming and neuroticism predisposes some individuals towards online gaming, and in line with the findings of Marengo et al. (2020; smartphone use disorder) and Kayiş et al. (2016; internet addiction), these traits appear prime candidates for further study of internet-related psychopathology. Other personality traits such as impulsivity (a neuroticism aspect), narcissism, sensation seeking, and closely linked notions to personality traits such as selfesteem or self-competence, hardiness, and self-efficacy, are worthy of consideration when investigating gaming disorder.

Third, considering that the Big Five personality traits (except for conscientiousness) have a trivial association with online gaming in some populations, the current study's nomothetic approach suggests that using an idiographic approach might shed light on the ESs disparities.

The very small to a small association of the Big Five personality traits with online gaming may be due to pooling all game genres in this meta-analysis, given the limitation of included studies that did not consider several game genres (i.e., action, adventure, role-playing, simulation, strategy, sports, and multiplayer OG) in sampling. Thus, future research might consider game genres when looking for the association between the Big Five personality traits and online gaming. Different personality traits are correlated with different game genres, for example neuroticism does not correlate with problematic gaming, but high extraversion and low neuroticism are associated with preference for action genre games (Braun et al., 2016) and high extraversion is correlated with music, party and casual games, while flight simulation, sports and other goal-oriented games have been reported to correlate with high scores in conscientiousness (Peever et al., 2012). In addition, game instruments' individual preferences (i.e., computer, tablet, mobile phone, game console) may also be worthy of examination in sampling. Furthermore, cognitions (i.e., perfectionism, cognitive salience, regret, and behavioral salience; Forrest, King, \& Delfabbro, 2016) and motives for gaming (Demetrovics et al., 2011; Moudiab \& Spada, 2019) may also help to determine which personality traits differentiate various online gaming habits.

\section{CONCLUSIONS}

The findings from our study showed that conscientiousness in any sample has a protective role and neuroticism, for some individuals, is a predisposing factor for online gaming.

Funding sources: This research did not receive any specific grant funding from agencies in the public, commercial, or not-for-profit sectors.

Authors' contribution: The authors' roles in the preparation of the study is as follows: Study concept and design: M
Akbari, M Spada, Sh Mohammadkhani \& M Seydavi. Data curation: A Jamaloo \& F Ayatmehr. Analysis and interpretation of data: M Akbari \& M Seydavi. Statistical analysis: M Akbari \& M Seydavi. Drafting the manuscript: M Akbari, M Seydavi \& M Spada. Final edition: M Akbari, M Seydavi, M Spada, Sh Mohammadkhani, and Sh Jamshidi, have read and edited the final version of the study. Approval of the version of the manuscript to be published: M Akbari, M Seydavi, M Spada, Sh Mohammadkhani, Sh Jamshidi, A Jamaloo, and F Ayatmehr.

Conflict of interests: The authors have no known competing financial interests or personal relationships that could have influenced this work.

\section{REFERENCES}

Akbari, M., Bahadori, M. H., Bouruki Milan, B., Caselli, G., \& Spada, M. M. (2021). Metacognitions as a predictor of online gaming in adolescents: Psychometric properties of the metacognitions about online gaming scale among Iranian adolescents. Addictive Behaviors, 118, 106904. https://doi.org/10.1016/ j. addbeh.2021.106904.

Aluja, A., Rossier, J., García, L. F., Angleitner, A., Kuhlman, M., \& Zuckerman, M. (2006). A cross-cultural shortened form of the ZKPQ (ZKPQ-50-cc) adapted to English, French, German, and Spanish languages. Personality and Individual Differences, 41(4), 619-628. https://doi.org/10.1016/j.paid. 2006.03.001.

Andreassen, C. S., Griffiths, M. D., Gjertsen, S. R., Krossbakken, E., Kvam, S., \& Pallesen, S. (2013). The relationships between behavioral addictions and the five-factor model of personality. Journal of Behavioral Addictions, 2(2), 90-99. https://doi.org/ 10.1556/jba.2.2013.003.

Barrett, P. T., Petrides, K. V., Eysenck, S. B. G., \& Eysenck, H. J. (1998). The Eysenck Personality Questionnaire: An examination of the factorial similarity of $\mathrm{P}, \mathrm{E}, \mathrm{N}$, and L across 34 countries. Personality and Individual Differences, 25(5), 805-819. https://doi.org/10.1016/S0191-8869(98)00026-9.

Blinka, L., Škařupová, K., \& Mitterova, K. (2016). Dysfunctional impulsivity in online gaming addiction and engagement. Cyberpsychology: Journal of Psychosocial Research on Cyberspace, 10(3). https://doi.org/10.5817/CP2016-3-5.

Borenstein, M. (2019). Common mistakes in meta-analysis and how to avoid them. Biostat Inc.

Borenstein, M., Hedges, L. V., Higgins, J. P., \& Rothstein, H. R. (2009). Introduction to meta-analysis. John Wiley \& Sons.

Borenstein, M., Hedges, L., Higgins, J., \& Rothstein, H. (2013). Comprehensive meta-analysis version 3 [software] Biostat, Englewood, NJ.

Borenstein, M., Higgins, J. P., Hedges, L. V., \& Rothstein, H. R. (2017). Basics of meta-analysis: I2 is not an absolute measure of heterogeneity. Research Synthesis Methods, 8(1), 5-18. https:// doi.org/10.1002/jrsm.1230.

Bouna-Pyrrou, P., Aufleger, B., Braun, S., Gattnar, M., Kallmayer, S., Wagner, H., ... Lenz, B. (2018). Cross-sectional and 
longitudinal evaluation of the social network use disorder and internet gaming disorder criteria. Frontiers in Psychiatry, 9, 692.

Brand, M., Young, K. S., Laier, C., Wölfling, K., \& Potenza, M. N. (2016). Integrating psychological and neurobiological considerations regarding the development and maintenance of specific Internet-use disorders: An Interaction of Person-AffectCognition-Execution (I-PACE) model. Neuroscience and Biobehavioral Reviews, 71, 252-266.

Braun, B., Stopfer, J. M., Müller, K. W., Beutel, M. E., \& Egloff, B. (2016). Personality and video gaming: Comparing regular gamers, non-gamers, and gaming addicts and differentiating between game genres. Computers in Human Behavior, 55, 406-412. https://doi.org/10.1016/j.chb.2015.09.041.

Carlisle, K. L. (2017). Personality, motivation, and Internet gaming disorder: Understanding the addiction. Old Dominion University.

Charlton, J. P., \& Danforth, I. D. (2010). Validating the distinction between computer addiction and engagement: Online game playing and personality. Behaviour \& Information Technology, 29(6), 601-613. https://doi.org/10.1080/01449290903401978.

Chory, R. M., \& Goodboy, A. K. (2011). Is basic personality related to violent and non-violent video game play and preferences? Cyberpsychology, Behavior, and Social Networking, 14(4), 191-198. https://doi.org/10.1089/cyber.2010.0076.

Collins, E., \& Freeman, J. (2013). Do problematic and non-problematic video game players differ in extraversion, trait empathy, social capital and prosocial tendencies? Computers in Human Behavior, 29(5), 1933-1940. https://doi.org/10.1016/j.chb.2013. 03.002.

Collins, E., Freeman, J., \& Chamarro-Premuzic, T. (2012). Personality traits associated with problematic and non-problematic massively multiplayer online role-playing game use. Personality and Individual Differences, 52(2), 133-138. https://doi.org/10. 1016/j.paid.2011.09.015.

Cosci, F., \& Fava, G. A. (2013). Staging of mental disorders: Systematic review. Psychotherapy and Psychosomatics, 82(1), 20-34. https://doi.org/10.1159/000342243.

De Hesselle, L. C., Rozgonjuk, D., Sindermann, C., Pontes, H. M., \& Montag, C. (2020). The associations between Big Five personality traits, gaming motives, and self-reported time spent gaming. Personality and Individual Differences, 110483. https:// doi.org/10.1016/j.paid.2020.110483.

Demetrovics, Z., Urbán, R., Nagygyörgy, K., Farkas, J., Griffiths, M. D., Pápay, O., ... Oláh, A. (2012). The development of the problematic online gaming questionnaire (POGQ). PloS One, 7(5), e36417.

Demetrovics, Z., Urbán, R., Nagygyörgy, K., Farkas, J., Zilahy, D., Mervó, B., ... Harmath, E. (2011). Why do you play? The development of the motives for online gaming questionnaire (MOGQ). Behavior Research Methods, 43(3), 814-825.

DeYoung, C. G. (2006). Higher-order factors of the Big Five in a multi-informant sample. Journal of Personality and Social Psychology, 91, 1138-1151. https://doi.org/10.1037/0022-3514. 91.6.1138.

DeYoung, C. G., Peterson, J. B., \& Higgins, D. M. (2002). Higherorder factors of the Big Five predict conformity: Are there neuroses of health? Personality and Individual Differences, 33, 533-552. https://doi.org/10.1016/S0191-8869(01)00171-4.
Dieris-Hirche, J., Pape, M., T. E Wildt, B. T., Kehyayan, A., Esch, M., ... Bottel, L. (2020). Problematic gaming behavior and the personality traits of video gamers: A cross-sectional survey. Computers in Human Behavior, 106, 106272.

Evans, J. D. (1996). Straightforward statistics for the behavioral sciences. Brooks/Cole Publishing.

Eysenck, S. B. G., Eysenck, H. J., \& Barrett, P. (1985). A revised version of the psychoticism scale. Personality and Individual Differences, 6, 21-29. https://doi.org/10.1016/0191-8869(85) 90026-1.

FAM, J. Y. (2018). Prevalence of internet gaming disorder in adolescents: A meta-analysis across three decades. Scandinavian Journal of Psychology, 59(5), 524-531. https://doi.org/10.1111/ sjop.12459.

Feng, W., Ramo, D., Chan, S., \& Bourgeois, J. (2017). Internet gaming disorder: Trends in prevalence 1998-2016. Addictive Behaviors, 75, 17. https://doi.org/10.1016/j.addbeh.2017.06.010.

Forrest, C. J., King, D. L., \& Delfabbro, P. H. (2016). The measurement of maladaptive cognitions underlying problematic video-game playing among adults. Computers in Human Behavior, 55, 399-405. https://doi.org/10.1016/j.chb.2015.09. 017.

Gervasi, A. M., La Marca, L., Costanzo, A., Pace, U., Guglielmucci, F., \& Schimmenti, A. (2017). Personality and Internet gaming disorder: A systematic review of recent literature. Current Addiction Reports, 4(3), 293-307. https://doi.org/10.1007/ s40429-017-0159-6.

Hirsh, J. B., DeYoung, C. G., \& Peterson, J. B. (2009). Metatraits of the Big Five differentially predict engagement and restraint of behavior. Journal of Personality, 77(4), 1085-1102. https://doi. org/10.1111/j.1467-6494.2009.00575.x.

Jiménez-Murcia, S., Fernández-Aranda, F., Granero, R., Chóliz, M., La Verde, M., Aguglia, E., ... Menchón, J. M. (2014). Video game addiction in gambling disorder: Clinical, psychopathological, and personality correlates. BioMed Research International, 2014.

Johnson, B. T. (2021). Toward a more transparent, rigorous, and generative psychology. Psychological Bulletin, 147(1), 1-15. http://dx.doi.org/10.1037/bul0000317.

Kayiş, A. R., Satici, S. A., Yilmaz, M. F., Şimşek, D., Ceyhan, E., \& Bakioğlu, F. (2016). Big five-personality trait and internet addiction: A meta-analytic review. Computers in Human Behavior, 63, 35-40. https://doi.org/10.1016/j.chb.2016.05. 012.

Khazaal, Y., Chatton, A., Rothen, S., Achab, S., Thorens, G., Zullino, D., \& Gmel, G. (2016). Psychometric properties of the 7item game addiction scale among french and German speaking adults. BMC Psychiatry, 16(1), 1-10. https://doi.org/10.1186/ s12888-016-0836-3.

Krueger R. F., Derriger J., Markon K. E., Watson D., \& Skodol A. E. C. (2015). Persönlichkeitsinventar für DSM-5 - Kurzform (PID5-BF) - Version für Erwachsene. Göttingen: Hogrefe.

Kuss, D. J., Van Rooij, A. J., Shorter, G. W., Griffiths, M. D., \& van de Mheen, D. (2013). Internet addiction in adolescents: Prevalence and risk factors. Computers in Human Behavior, 29(5), 1987-1996. https://doi.org/10.1016/j.chb.2013.04.002.

Laier, C., Wegmann, E., \& Brand, M. (2018). Personality and cognition in gamers: Avoidance expectancies mediate the 
relationship between maladaptive personality traits and symptoms of Internet-gaming disorder. Frontiers in Psychiatry, 9, 304. https://doi.org/10.3389/fpsyt.2018.00304.

Lemmens, J. S., Valkenburg, P. M., \& Gentile, D. A. (2015). The Internet gaming disorder scale. Psychological Assessment, 27(2), 567. https://doi.org/10.1037/pas0000062.

Lemmens, J. S., Valkenburg, P. M., \& Peter, J. (2009). Development and validation of a game addiction scale for adolescents. Media Psychology, 12(1), 77-95. https://doi.org/10.1080/ 15213260802669458.

Li, H., Zou, Y., Wang, J., \& Yang, X. (2016). Role of Stressful Life Events, Avoidant Coping Styles, and Neuroticism in Online Game Addiction among College Students: A Moderated Mediation Model. Frontiers in Psychology, 7, 1794. https://doi. org/10.3389/fpsyg.2016.01794.

Liao, Z., Huang, Q., Huang, S., Tan, L., Shao, T., Fang, T., ... Shen, H. (2020). Prevalence of Internet Gaming Disorder and Its association with personality traits and gaming characteristics among Chinese adolescent gamers. Frontiers in Psychiatry, 11, 1266.

López Fernández, F. J. (2020). Personality and Video Games: The role of personality in normal and disordered videogaming, motives to play, and aggression (Doctoral dissertation, Universitat Jaume I).

López-Fernández, F. J., Mezquita, L., Griffiths, M. D., Ortet, G., \& Ibáñez, M. I. (2020). The role of personality on disordered gaming and game genre preferences in adolescence: gender differences and person-environment transactions. Adicciones, 1370.

Marengo, D., Sindermann, C., Häckel, D., Settanni, M., Elhai, J. D., \& Montag, C. (2020). The association between the Big Five personality traits and smartphone use disorder: A meta-analysis. Journal of Behavioral Addictions, 9(3), 534-550. https:// doi.org/10.1556/2006.2020.00069.

Mehroof, M., \& Griffiths, M. D. (2010). Online gaming addiction: The role of sensation seeking, self-control, neuroticism, aggression, state anxiety, and trait anxiety. Cyberpsychology, Behavior, and Social Networking, 13(3), 313-316. https://doi. org/10.1089/cyber.2009.0229.

Mentzoni, R. A., Brunborg, G. S., Molde, H., Myrseth, H., Skouverøe, K. J. M., Hetland, J., \& Pallesen, S. (2011). Problematic video game use: Estimated prevalence and associations with mental and physical health. Cyberpsychology, Behavior, and Social Networking, 14(10), 591-596. https://doi.org/10. 1089/cyber.2010.0260.

Mihara, S., \& Higuchi, S. (2017). Cross-sectional and longitudinal epidemiological studies of Internet Gaming Disorder: A systematic review of the literature. Psychiatry and Clinical Neurosciences, 71(7), 425-444. https://doi.org/10.1111/pcn.12532.

Moher, D., Liberati, A., Tetzlaff, J., \& Altman, D. G. The PRISMA Group (2009) Preferred reporting items for systematic reviews and meta-analyses: The PRISMA statement. PloS Medicine, 6(7): e1000097. https://doi.org/10.1371/journal.pmed.1000097.

Montag, C., Flierl, M., Markett, S., Walter, N., Jurkiewicz, M., \& Reuter, M. (2011). Internet addiction and personality in firstperson-shooter video gamers. Journal of Media Psychology: Theories, Methods, and Applications, 23(4), 163. https://doi.org/ 10.1027/1864-1105/a000049.
Moudiab, S., \& Spada, M. M. (2019). The relative contribution of motives and maladaptive cognitions to levels of Internet Gaming Disorder. Addictive Behaviors Reports, 9, 100160. https://doi.org/10.1016/j.abrep.2019.100160.

Müller, K. W., Beutel, M. E., Egloff, B., \& Wölfling, K. (2014). Investigating risk factors for Internet gaming disorder: A comparison of patients with addictive gaming, pathological gamblers and healthy controls regarding the Big Five personality traits. European Addiction Research, 20(3), 129-136. https://doi.org/10.1159/000355832.

Munno, D., Cappellin, F., Saroldi, M., Bechon, E., Guglielmucci, F., Passera, R., \& Zullo, G. (2017). Internet Addiction Disorder: Personality characteristics and risk of pathological overuse in adolescents. Psychiatry Research, 248, 1-5. https://doi.org/10. 1016/j.psychres.2016.11.008.

Paulus, F. W., Ohmann, S., Von Gontard, A., \& Popow, C. (2018). Internet gaming disorder in children and adolescents: A systematic review. Developmental Medicine and Child Neurology, 60(7), 645-659. https://doi.org/10.1111/dmcn.13754.

Peever, N., Johnson, D., Gardner, J. (2012, July). Personality \& video game genre preferences. In Proceedings of the 8th australasian conference on interactive entertainment: Playing the system (pp. 1-3).

Pontes, H. M., Kiraly, O., Demetrovics, Z., \& Griffiths, M. D. (2014). The conceptualization and measurement of DSM-5 Internet Gaming Disorder: The development of the IGD-20 test. PloS One, 9(10), e110137. https://doi.org/10.1371/journal.pone.0110137.

Pontes, H. M., Stavropoulos, V., \& Griffiths, M. D. (2020). Emerging insights on internet gaming disorder: Conceptual and measurement issues. Addictive Behaviors Reports, 11. https:// doi.org/10.1016/j.abrep.2019.100242.

Protogerou, C., \& Hagger, M. S. (2020). A checklist to assess the quality of survey studies in psychology. Methods in Psychology, 3, 100031. https://doi.org/10.1016/j.metip.2020.100031.

Rehbein, F., Kliem, S., Baier, D., Mößle, T., \& Petry, N. M. (2015). Prevalence of internet gaming disorder in German adolescents: Diagnostic contribution of the nine DSM-5 criteria in a statewide representative sample. Addiction, 110(5), 842-851. https:// doi.org/10.1111/add.12849.

Reyes, M. E. S., Davis, R. D., Lim, R. A. N. N., Lim, K. R. S., Paulino, R. F., Carandang, A. M. D., \& Azarraga, M. G. S. (2019). Five-factor model traits as predictors of pathological gaming among selected Filipino gamers. Psychological Studies, 64(2), 213-220. https://doi.org/10.1007/s12646-019-00498-y.

Şalvarlı, Ş. İ., \& Griffiths, M. D. (2019). Internet gaming disorder and its associated personality traits: A systematic review using PRISMA guidelines. International Journal of Mental Health and Addiction, 1-23. https://doi.org/10.1007/s11469-019-00081-6.

Sejud, L. R. (2013). The differential role of impulsivity, neuroticism, and negative affect within and across scores on measures of behavioral addiction and substance abuse (Doctoral dissertation, Baylor University).

Seong, W., Hong, J., Kim, S. M., Kim, S., \& Han, D. H. (2019). Personality and psychological factors in individuals with problematic Internet game play. Frontiers in Psychiatry, 10, 583. https://doi.org/10.3389/fpsyt.2019.00583.

Stevens, M. W., Dorstyn, D., Delfabbro, P. H., \& King, D. L. (2020). Global prevalence of gaming disorder: A systematic review and 
meta-analysis. Australian \& New Zealand Journal of Psychiatry, 0004867420962851.

Sugaya, N., Shirasaka, T., Takahashi, K., \& Kanda, H. (2019). Biopsychosocial factors of children and adolescents with internet gaming disorder: A systematic review. BioPsychoSocial Medicine, 13(1), 3. https://doi.org/10.1186/s13030-019-0144-5.

Teng, C. I., Lo, S. K., \& Lin, Y. L. (2012). Online gamer personality and weekday gaming tendency. African Journal of Business Management, 6(2), 704-710. https://doi.org/10.5897/AJBM10.1610.

Torres-Rodríguez, A., Griffiths, M. D., Carbonell, X., \& Oberst, U. (2018). Internet gaming disorder in adolescence: Psychological characteristics of a clinical sample. Journal of Behavioral Addictions, 7(3), 707-718. https://doi.org/10.1556/2006.7.2018.75.

Vollmer, C., Randler, C., Horzum, M. B., \& Ayas, T. (2014). Computer game addiction in adolescents and its relationship to chronotype and personality. Sage Open, 4(1), 2158244013518054.
Wang, H., Jin, C., Yuan, K., Shakir, T. M., Mao, C., Niu, X., ... Zhang, M. (2015). The alteration of gray matter volume and cognitive control in adolescents with internet gaming disorder. Frontiers in Behavioral Neuroscience, 9, 64.

Wang, Q., Ren, H., Long, J., Liu, Y., \& Liu, T. (2019). Research progress and debates on gaming disorder. General Psychiatry, 32, e100071. http://dx.doi.org/10.1136/gpsych-2019-100071.

Wittek, C. T., Finserås, T. R., Pallesen, S., Mentzoni, R. A., Hanss, D., Griffiths, M. D., \& Molde, H. (2016). Prevalence and predictors of video game addiction: A study based on a national representative sample of gamers. International Journal of Mental Health, 14, 672-686. https://doi.org/10.1007/s11469015-9592-8.

Yee, N. (2006). Motivations for play in online games. CyberPsychology \& Behavior, 9(6), 772-775. https://doi.org/10.1089/ cpb.2006.9.772. 